Dhaka Univ. J. Biol. Sci. 26(2): 159-166, 2017 (July)

\title{
EFFECTS OF NATURAL AND COMMERCIAL DIETS ON GROWTH, REPRODUCTIVE PERFORMANCES AND EMBRYOGENESIS OF ZEBRAFISH DANIO RERIO
}

\author{
Md Golam RabBanE* AND MD RaKibuR RAHMAN \\ Department of Fisheries, University of Dhaka, Dhaka-1000, Bangladesh \\ Key words: Commercial diets, Growth, Reproduction, Embryogenesis, Zebrafish
}

\begin{abstract}
This study evaluated the effects of five diets (diet 1: Dried tubifex, diet 2: Artemia, diet 3: Artemia and commercial pellet feed, diet 4: Spirulina and commercial pellet feed; diet 5: commercial pellet feed) on growth, reproductive performances and embryogenesis of zebrafish Danio rerio for a period of 62 days. Significantly higher specific growth rate was found in diet 5 when compared with diet 1 but no significant difference was observed between diet 2, 3,4 and 5 . Mean weight and length gain were significantly greater in zebrafish fed diet 5 than diets $1-4$. While $100 \%$ survival was found in diet 4 , the lowest level was $90.26 \pm 1.06 \%$ in diet 1 . Mean spawning success was significantly higher in zebrafish fed diet 5 than in those fed diets $1-4$. Mean fertilization and hatching rates were higher in the fish fed diet $3-5$ than in diets 1 and 2 . Zebrafish consumed commercial pellet feed only resulted in more viable offsprings and grown better. Results suggested that commercial pellet is suitable in zebrafish culture for maximum growth and production of viable offspring in laboratory condition.
\end{abstract}

\section{Introduction}

Zebrafish Danio rerio has become one of the important models over the world in the field of scientific research. It is a small tropical fresh water fish commonly found in Bangladesh, India, Nepal and Myanmar. Currently this fish has been widely used as model fish in aquaculture research ${ }^{(1-2)}$. Zebrafish have some benefits in the research area of nutrition and growth because it possesses the most developed genomic program compared to that of any other aquaculture fish, they are easy to maintain and breed, have short generational duration and high fecund. These benefits allow the use of the zebrafish as an excellent model in the area of aquaculture nutrition.

Growth and reproduction are the main parameters that are directly linked with profitability and productivity of fish production ${ }^{(3)}$. Zebrafish are omnivorous and growth rates mainly depend on diet as well as age and season, with rapid growth in early life stage in monsoon ${ }^{(4)}$. Although pertinent literatures are available on zebrafish as model animal in research but a few documents are available in nutritional requirement specially

*Author for correspondence: <rabbane@du.ac.bd> 
protein requirement of zebrafish ${ }^{(1,5-7)}$. Thus there is a need to study protein requirement of zebrafish for proper growth and reproduction ${ }^{(8)}$. Therefore, the study was conducted to determine the effect of 3 natural and 1 commercially available diet on growth, reproduction and embryogenesis of zebrafish.

\section{Material and Methods}

Glo-zebrafish (transgenic red fluorescent) was used in this research. Fish were purchased from Kataban Aquarium fish market, Dhaka and transported with oxygen filled plastic bags and stocked to the experimental systems. The experiment was conducted in 15 experimental aquaria (4L capacity) at the Department of Fisheries, University of Dhaka. All those aquaria were randomly placed in a steel made rack. The study was undertaken between June and September, 2015 over a period of 78 days.

This was a one factorial study with five feed in triplicates. All aquaria were filled in with tap water and labeled according to experimental design. Each aquarium was stocked at 21 fish. Aeration (Sobo aquarium air pump SB-348A) was given by electricity for $24 \mathrm{hrs}$ during the experimental period.

Five natural and commercial feed combinations were used in this experiment such as diet-1 dried tubifex, diet-2 live Artemia, diet-3 Artemia with commercial pellet feed as complementary feed, diet- 4 spirulina with commercial pellet feed and diet- 5 commercial pellet feed only. Artemia cyst (Great Salt Lake, USA) were also purchased from Kataban aquarium fish market and decapsulated at 35-40 ppt salinity ${ }^{(9)}$. Spirulina powder was obtained from BCSIR (Bangladesh Council of Science and Industrial Research, Dhaka) as it is widely used as both human and animal food. The commercial feed was drawn from Aquarium fish market in a much fined box which was wrapped with aluminum foil named "TetraBits Complete, Germany" as a complete and balanced nutritional staple food ideal for all mid-water and bottom feeding fish. The proximate composition of feeds used in this study is provided in Table 1 and it was based on manufacture instructions.

Fish were fed different feeds at satiation level. Satiation point was a 5 min time limit that a fish no longer actively search for food. The experimental aquaria were monitored everyday to observe the behavior of fishes. All aquaria were held clean to provide hygienic condition. Water quality variables such as $\mathrm{pH}$, temperature, dissolved oxygen concentration and total dissolved solid (TDS) were measured by using multiparameter kit (Model: HI9828 Multiparameter, HANNA instruments, woonsocket. RI, USA). Water (4L) was changed in each aquarium every one day interval. 
Table 1. Proximate composition of the feeds used in the experiment.

\begin{tabular}{lllllll}
\hline Feeds & $\begin{array}{l}\text { Protein } \\
(\%)\end{array}$ & $\begin{array}{l}\text { Mineral } \\
\text { components } \\
(\%)\end{array}$ & $\begin{array}{l}\text { Fat } \\
(\%)\end{array}$ & $\begin{array}{l}\text { Moisture } \\
(\%)\end{array}$ & $\begin{array}{l}\text { Crude } \\
\text { fibre } \\
(\%)\end{array}$ & Reference \\
\hline Tubifex & $50-60$ & 6.9 & 10 & 4 & 2 & $\begin{array}{l}\text { SF dried frozen } \\
\text { Tubifex, Thailand }\end{array}$ \\
Artemia & 39.4 & 28.1 & 4.96 & 9.6 & 5 & GSL, USA \\
$\begin{array}{l}\text { Spirulina } \\
\text { Commercial } \\
\text { pellet feed }\end{array}$ & $60-70$ & 8 & $0.27-0.47$ & 7 & $10-20$ & $\begin{array}{l}\text { BCSIR, Dhaka } \\
\text { TetraBits, Germany }\end{array}$ \\
\hline
\end{tabular}

To observe growth performance 7 fish was sampled from each aquarium. During each sampling, fish was caught by fine mesh scoop net and held in a concentration of 2phenoxyethanol. The concentration was made of $18 \mu \mathrm{l}$ 2-phenoxyethanol and $60 \mathrm{ml}$ water.

The following formulae were used in calculating weight gain, condition factor, specific growth rate $(\mathrm{SGR})$, gender weight gain $(\mathrm{g})$, length gain $(\mathrm{cm})$, food conversion ratio (FCR) and survival rate $(\%)^{(8,10)}$.

Weight gain $(\mathrm{g})=$ Mean final weight - Mean initial weight

Gender weight gain $(g)=\frac{W f}{W m}$

$\mathrm{Wf}=$ Female weight gain, $\mathrm{Wm}=$ Male weight gain

Specific growth rate $(g)=\frac{\left(\operatorname{In~} \mathrm{W}_{2}-\mathrm{In} \mathrm{W}_{1}\right)}{\left(\mathrm{T}_{2}-\mathrm{T}_{1}\right)} \times 100$

where, $\mathrm{W}_{2}=$ Mean final weight $(\mathrm{g}), \mathrm{W}_{1}=$ Mean initial weight $(\mathrm{g}), \mathrm{T}_{2}=$ Time at the end of the experiment, $\mathrm{T}_{1}=$ Time at the start of the experiment.

Condition factor, $\mathrm{K}=\frac{\text { Fish weight }}{{\text { (Fish length })^{3}}^{3}} 100$

Length gain $(\mathrm{cm})=$ Mean final length $(\mathrm{cm})-$ Mean initial length $(\mathrm{cm})$

Food conversion ratio, FCR $=\frac{\text { Feed }(\mathrm{g}) \text { consumed by the fish }}{\text { Weight }(\mathrm{g}) \text { gain of the fish }\left(\mathrm{W}_{2}-\mathrm{W}_{1}\right)}$

Survival rate $(\%)=\frac{\text { Number of fish harvested }}{\text { Number of fish stocked }} \times 100$ 
Five pairs of male and female from each aquarium was held in breeding aquaria (1 male : 1 female ratio) for natural spawning and fertilization. The parameters for reproductive performance were measured using following equations ${ }^{(10)}$ :

$$
\begin{aligned}
& \text { Spawning success }(\%)=\frac{\text { No. of spawning events per dietary treatment }}{\text { No. of pairs established }} \times 100 \\
& \text { Fertilization rate }(\%)=\frac{\text { Number of fertilized embryos }}{\text { Total number of embryos produced at a spawning event }} \times 100
\end{aligned}
$$

Hatching rate $(\%)=\frac{\text { Number of hatched eggs }}{\text { Total number of fertilized embryos }} \times 100$

Embryogenesis of zebrafish at different developmental stages was observed using a microscope (MBL2000, Krüss, Germany) with transmitted illumination and 40x magnification. Stages studied were: cleavage (3/4 - $\left.2 \frac{1 / 4}{\mathrm{hrs}}\right)$, gastrula (5 1/4 - $\left.10 \mathrm{hrs}\right)$, segmentation (10 - $24 \mathrm{hrs})$, pharyngula (24 - $48 \mathrm{hrs)}$ and hatching (48 - $72 \mathrm{hrs)}$.

All per cent data were transformed into square root before statistical analysis. Growth rate, FCR, survival rate, spawning rate and fertilization rate were analyzed by using 1-way ANOVA followed by Tukey's HSD post hoc for multiple comparisons. Level of significance considered in this study was $\mathrm{p}<0.05$.

\section{Results and Discussion}

Cent percent survival rate was obtained when fed spirulina (Table 2) and lowest in diet $1(90.26 \pm 1.02)$. Gonzales ${ }^{(10)}$ found $100 \%$ survival rate in Artemia + AP Hatch, Artemia + Hatchfry Encapsulon and Artemia + krill : flake mix + AP Hatch. He also found more than $90 \%$ survival for other combinations whereas present study received 90 to $100 \%$ survival rate. Significantly lowest and best FCR $(2.15 \pm 0.04)$ was observed in zebrafish fed commercial pellet because a low FCR value is an indicator of better feed utilization efficiency. Toguyeni et al.(11) suggested that feeding behaviour has an effect on the efficiency of food conversion. Therefore, commercial pellet feed may be very efficient for feeding.

Significantly higher weight $(0.12 \pm 0.00 \mathrm{~g})$ and length $(0.62 \pm 0.03 \mathrm{~cm})$ were measured in zebrafish after 62 days culture fed commercial pellet (Table 2). Similar but lower weight was detected in the fish fed other four diets (diets 1 - 4). However, lower length $(0.20 \pm 0.02 \mathrm{~cm})$ was determined in zebrafish when fed dried tubifex. Higher SGR $(1.51 \pm$ $0.16 \% / d$ ) was measured in zebrafish upon completion of 62 days culture fed commercial pellet feed (Table 2). Lower SGR $(0.52 \pm 0.10)$ was found when fed dried tubifex. Diets 2 4 were similar to the diets 1 and 5 . 
Table 2. Performances of zebrafish Danio rerio fed different diets.

\begin{tabular}{lccccc}
\hline Variables & \multicolumn{5}{c}{ Diets } \\
\cline { 2 - 6 } & \multicolumn{1}{c}{1} & 2 & 3 & 4 & 5 \\
\hline Survival rate (\%) & $90.26 \pm 1.02$ & $92.15 \pm 0.94$ & $95.42 \pm 2.86$ & $100.00 \pm 0.00$ & $93.08 \pm 4.35$ \\
FCR & $3.19 \pm 0.06^{\mathrm{a}}$ & $2.93 \pm 0.17^{\mathrm{ab}}$ & $2.73 \pm 0.07^{\mathrm{b}}$ & $2.66 \pm 0.04^{\mathrm{b}}$ & $2.15 \pm 0.04^{\mathrm{c}}$ \\
SGR (\%) & $0.52 \pm 0.10^{\mathrm{a}}$ & $1.25 \pm 0.33^{\mathrm{ab}}$ & $1.17 \pm 0.11^{\mathrm{ab}}$ & $1.17 \pm 0.03^{\mathrm{ab}}$ & $1.51 \pm 0.12^{\mathrm{b}}$ \\
Daily weight gain (g) & $0.03 \pm 0.00^{\mathrm{a}}$ & $0.08 \pm 0.02^{\mathrm{a}}$ & $0.07 \pm 0.004^{\mathrm{a}}$ & $0.07 \pm 0.01^{\mathrm{a}}$ & $0.12 \pm 0.01^{\mathrm{b}}$ \\
Length gain (cm) & $0.20 \pm 0.03^{\mathrm{a}}$ & $0.44 \pm 0.07^{\mathrm{bc}}$ & $0.40 \pm 0.05^{\mathrm{ab}}$ & $0.40 \pm 0.04^{\mathrm{ab}}$ & $0.62 \pm 0.03^{\mathrm{c}}$ \\
Gender weight gain (g) & $1.12 \pm 0.03$ & $1.19 \pm 0.06$ & $1.18 \pm 0.02$ & $1.176 \pm 0.048$ & $1.196 \pm 0.032$ \\
Condition factor & $1.92 \pm 0.02$ & $1.87 \pm 0.01$ & $1.92 \pm 0.04$ & $2.01 \pm 0.06$ & $1.86 \pm 0.04$ \\
\hline
\end{tabular}

Values are mean \pm SEM in the same row with different superscripts are significantly different (ANOVA; HSD; $\mathrm{p}<0.05$ ).

To develop a standard diet, Kaushnik et al.(12) performed a research of feeding zebrafish larvae with a formulated feed right from first feeding onward. Growth of zebrafish fed compound feed was very good, reaching a total length of $23 \pm 4 \mathrm{~mm}$ in 9 weeks. Carvalho et al.(13) conducted an experiment with 4 different diets (Artemia nauplii, a commercial, a purified, a practical diet). The best overall larval performance was achieved in the group fed Artemia nauplii (14.3 mm standard length and $46.1 \mathrm{mg}$ wet weight). However, Gonzales ${ }^{(10)}$ has not found any effect of particular feed on zebrafish growth. However, the present study found higher growth in commercial pellet feed fed zebrafish that might be due to the balanced combination of ingredients in commercial feed.

No significant difference in gender weight gain of zebrafish was observed among different diets (Table 2) which is an agreement with the findings of Gonzales(10) who obtained 1.12 to 2.92 gender weight ratio from seven different diets. Higher condition factor $(2.01 \pm 0.06)$ was measured in zebrafish at 62 days fed spirulina and commercial pellet feed (Diet 4; Table 2). Lower value (1.86 \pm 0.07$)$ of condition factor was determined in zebrafish at 62 days fed diet 5. No significant difference of condition factor also obtained by Siccardi et al.(14) when zebrafish were fed different commercial and laboratory diets. The lack of significant difference of condition index indicates a better healthy condition(14).

Significantly higher spawning success $(95.00 \pm 2.87)$ was obtained in diet 5 and lowest in diet 1 whereas there was no significant difference between diets 2 and 3 . Significantly higher fertilization and hatch rate were observed in diets 4, 5 than diet 1 and 2 (Table 3). The significantly highest hatch rate was found in diet $5(76.64 \pm 3.19)$ followed by diet 4 and 3. 
Table 3. Reproductive performances of zebrafish Danio rerio fed five diets.

\begin{tabular}{lccccc}
\hline \multirow{2}{*}{ Variables } & \multicolumn{5}{c}{ Diets } \\
\cline { 2 - 6 } & 1 & 2 & 3 & 4 & 5 \\
\hline Spawning success (\%) & $20.37 \pm 0.97^{\mathrm{a}}$ & $35.48 \pm 3.87^{\mathrm{b}}$ & $43.17 \pm 3.66^{\mathrm{b}}$ & $66.32 \pm 2.30^{\mathrm{c}}$ & $95 \pm 2.87^{\mathrm{d}}$ \\
Fertilization rate (\%) & $54.51 \pm 3.47^{\mathrm{a}}$ & $57.81 \pm 3.02^{\mathrm{a}}$ & $81.37 \pm 2.44^{\mathrm{b}}$ & $83.07 \pm 1.42^{\mathrm{b}}$ & $85.50 \pm 2.54^{\mathrm{b}}$ \\
Hatch rate (\%) & $46.00 \pm 3.62^{\mathrm{a}}$ & $47.90 \pm 01.42^{\mathrm{a}}$ & $68.03 \pm 3.90^{\mathrm{b}}$ & $68.58 \pm 1.90^{\mathrm{b}}$ & $76.64 \pm 3.19^{\mathrm{b}}$ \\
\hline
\end{tabular}

Values are mean \pm SEM $(n=21)$. Values in the same row with different superscripts denote significant difference (ANOVA; HSD, $\mathrm{P}<0.05$ ).

Table 4. Survival rate (\%) of embryos zebrafish Danio rerio at different periods of embryogenesis.

\begin{tabular}{lccccc}
\hline \multirow{2}{*}{$\begin{array}{l}\text { Duration of } \\
\text { embryogenesis }\end{array}$} & \multicolumn{5}{c}{ Embryos survival rate (\%) of different diets } \\
\cline { 2 - 6 } & 1 & 2 & 3 & 4 & 5 \\
\hline Cleavage & $54.51 \pm 3.47^{\mathrm{a}}$ & $57.81 \pm 3.02^{\mathrm{a}}$ & $81.37 \pm 2.44^{\mathrm{b}}$ & $83.07 \pm 1.42^{\mathrm{b}}$ & $85.50 \pm 2.54^{\mathrm{b}}$ \\
Gastrula & $54.51 \pm 3.47^{\mathrm{a}}$ & $57.81 \pm 3.02^{\mathrm{a}}$ & $79.08 \pm 1.31^{\mathrm{b}}$ & $83.07 \pm 1.42^{\mathrm{b}}$ & $85.50 \pm 2.54^{\mathrm{b}}$ \\
Segmentation & $50.86 \pm 0.33^{\mathrm{a}}$ & $51.79 \pm 0.40^{\mathrm{a}}$ & $74.36 \pm 1.14^{\mathrm{b}}$ & $77.47 \pm 0.57^{\mathrm{bc}}$ & $80.70 \pm 0.59^{\mathrm{c}}$ \\
Pharyngula & $47.61 \pm 0.39^{\mathrm{a}}$ & $51.05 \pm 0.69^{\mathrm{a}}$ & $71.15 \pm 0.17^{\mathrm{b}}$ & $71.74 \pm 1.74^{\mathrm{b}}$ & $78.40 \pm 0.74^{\mathrm{c}}$ \\
\hline
\end{tabular}

Values are (mean \pm SEM) of triplicate groups of 21 fish from each diet. Means of embryos at significant difference in the same line with different superscripts $(p<0.05)$.

Poor spawning success, fertilization rate and hatch rate in diets $1-3$ might be due to feed quality ${ }^{(15,10)}$. Gonzales ${ }^{(10)}$ did not find any difference in fertilization rate in zebrafish but $80 \%$ fertilization rate in indoor zebrafish culture. Karga and Mandal ${ }^{(8)}$ observed only $53.62 \%$ hatch rate when four diets were tested.

In cleavage, gastrula, segmentation and hatching stages, the survival rate of embryos in diets 3 - 5 were significantly higher than diets 1 and 2 (Table 4). Highest value (85.50 \pm 2.54) was measured in zebrafish at cleavage period fed commercial pellet and the lowest value $(54.51 \pm 3.47)$ was determined at cleavage period fed dried tubifex. In Pharyngula stage highest value $(76.64 \pm 3.19)$ was obtained in diet 5 followed by diets 4 and 3 . Kimmel et al.(16) reported that fertilized eggs grow normally at temperatures between 25 and $33^{\circ} \mathrm{C}$ but abnormality and mortality occurs at temperature higher or below this level. Therefore, the variation of survival rates in different treatments observed in the current study could be due to the difference of feed quality. Water quality variables such as temperature, $\mathrm{pH}, \mathrm{DO}$ and TDS were $29.32 \pm 0.33,8.35 \pm 0.18,3.72 \pm 0.24$ and $195.33 \pm 14.56$ respectively were in acceptable range during the study. 
This study has clearly demonstrated that commercial pellet is the best for indoor culture of zebrafish indicated by maximum growth, yield and reproduction. However, spirulina and commercial pellet had similar (100\%) survival.

\section{Acknowledgements}

Authors are grateful to the Ministry of Science and Technology, Government of the People's Republic of Bangladesh for their financial support to conduct this research.

\section{References}

1. Ulloa PE, P Iturra, R Neira and C Araneda 2011. Zebrafish as a model organism for nutrition and growth: towards comparative studies of nutritional genomics applied to aquacultured fishes. Rev. Fish Biol. Fish. 21: 649-666.

2. Ribas L and F Piferrer 2013. The zebrafish (Danio rerio) as a model organism, with emphasis on applications for finfish aquaculture research. Rev. Aquac. 5: 1-32.

3. De-Santis C, D Jerry D 2007. Candidate growth genes in finfish - Where should we be looking? Aquaculture 272: 22-38.

4. Spence R, MK Fatema, S Ellis, ZF Ahmed and C Smith 2007. Diet, growth and recruitment of wild zebrafish in Bangladesh. J. Fish Biol. 71(1): 304-309.

5. Lawrence $C$ 2007. The husbandry of zebrafish (Danio rerio): A review. Aquaculture 269: 1-20.

6. Lieschke GJ and PD Currie 2007. Animal models of human disease: zebrafish swim into view. Nat. Rev. Genet. 8: 353-367.

7. Rabbane MG, MF Ahmed, MS Alam and MM Hossain 2016. Culture, reproduction and embryogenesis of wild zebrafish (Danio rerio) in laboratory condition. Dhaka Univ. J. Biol. Sci. 25(2): 139-148.

8. Karga J and SC Mandal 2016. Effect of different feeds on the growth, survival and reproductive performance of zebrafish, Danio rerio (Hamilton, 1822). Aquaculture Nutrition 23: 406-413.

9. Verschuere LG, G Rombaut, J Huys, P Dhont, Sorgeloos and W Verstraete 1999. Microbial control of the culture of Artemia juveniles through preemptive colonization by selected bacterial strains. Appl. Environ. Microbiol. 65: 2527-2533.

10. Gonzales JM 2012. Preliminary evaluation on the effects of feeds on the growth and early reproductive performance of Zebrafish (Danio rerio). J. Amer. Assoc. Lab. Anim. Sci. 51(4): 412-417.

11. Toguyeni A, B Fauconneau and T Boujard 1997. Feeding behaviour and food utilisation in tilapia, Oreochromis niloticus: Effect of sex ratio and relationship with the endocrine status. Physiology \& Behavior 62: 273-279.

12. Kaushik S, I Georga and G Koumoundouros 2011. Growth and body composition of zebrafish (Danio rerio) larvae fed a compound feed from first feeding onward: toward implications on nutrient requirements. Zebrafish 8(2): 87-95.

13. Carvalho AP, L Araújo and MM Santos 2006. Rearing zebrafish (Danio rerio) larvae without live food: Evaluation of a commercial, a practical and a purified starter diet on larval performance. Aquaculture Research 37(11): 1107-1111. 
14. Siccardi IAJ, HW Garris, WT Jones, DB Moseley, LR D'abramo and SA Watts 2009. Growth and survival of zebrafish (Danio rerio) fed different commercial and laboratory diets. Zebrafish 6(3): 275-280.

15. Markovich ML, NV Rizzuto and PB Brown 2007. Diet affects spawning in zebrafish. Zebrafish 4(1): 69-74.

16. Kimmel CB, WW Ballard, SR Kimmel, B Ullmann and TF Schilling 1995. Stages of embryonic development of zebrafish. Developmental Dynamics 203: 253-310.

(Manuscript received on 2 April, 2017; revised on 8 May, 2017) 